\title{
Opening Holes in the Blanket of Inhibition: Localized Lateral Disinhibition by VIP Interneurons
}

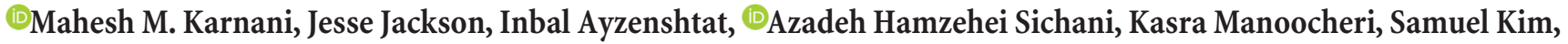 \\ and Rafael Yuste \\ Neurotechnology Center, Department of Biological Sciences, Columbia University, New York, New York 10027
}

Inhibitory interneurons in the neocortex often connect in a promiscuous and extensive fashion, extending a "blanket of inhibition" on the circuit. This raises the problem of how can excitatory activity propagate in the midst of this widespread inhibition. One solution to this problem could be the vasoactive intestinal peptide (VIP) interneurons, which disinhibit other interneurons. To explore how VIP interneurons affect the local circuits, we use two-photon optogenetics to activate them individually in mouse visual cortex in vivo while measuring their output with two-photon calcium imaging. We find that VIP interneurons have narrow axons and inhibit nearby somatostatin interneurons, which themselves inhibit pyramidal cells. Moreover, via this lateral disinhibition, VIP cells in vivo make local and transient "holes" in the inhibitory blanket extended by SOM cells. VIP interneurons, themselves regulated by neuromodulators, may therefore enable selective patterns of activity to propagate through the cortex, by generating a "spotlight of attention".

Key words: disinhibition; interneuron; neocortex; vasoactive intestinal peptide; VIP

\section{Significance Statement}

Most inhibitory interneurons have axons restricted to a nearby area and target excitatory neighbors indiscriminately, raising the issue of how neuronal activity can propagate through cortical circuits. Vasoactive intestinal peptide-expressing interneurons (VIPs) disinhibit cortical pyramidal cells through inhibition of other inhibitory interneurons, and they have very focused, "narrow" axons. By optogenetically activating single VIPs in live mice while recording the activity of nearby neurons, we find that VIPs break open a hole in blanket inhibition with an effective range of $\sim 120 \mu \mathrm{m}$ in lateral cortical space where excitatory activity can propagate.

\section{Introduction}

Local inhibition through GABAergic inhibitory interneurons (INs) is a crucial element of neocortical information processing. Lateral inhibition is a fundamental principle in neuronal networks (Harris and Mrsic-Flogel, 2013; Karnani et al., 2014) first characterized 60 years ago (Hartline et al., 1956). In the rodent neocortex disynaptic lateral inhibition between nearby pyramidal cells (PCs) is thought to work through somatostatin-expressing INs (SOMs; Kapfer et al., 2007; Silberberg and Markram, 2007; Adesnik et al., 2012). SOMs constitute a major division of neocortical INs along with parvalbumin (PV)- and vasoactive intestinal peptide (VIP)-expressing INs.

\footnotetext{
Received Oct. 2, 2015; revised Dec. 26, 2015; accepted Jan. 20, 2016.

Author contributions: M.M.K., J.J., and R.Y. designed research; M.M.K., J.J., I.A., A.H.S., K.M., and S.K. performed research; M.M.K., J.J., and I.A. analyzed data; M.M.K. wrote the paper.

This work was funded by NIH R01EY011787 and DP1EY024503, NIMH (R01MH101218, R01MH100561), DARPA SIMPLEX n66001-15-C-4032M, and ARO W911NF-12-1-0594(MURI) to R.Y., HFSP long-term fellowship to M.M.K., Canadian Institute for Health Research fellowship to J.J. and Marie Curie IOF to I.A. We thank Darcy Peterka, Benjamin Shababo, Yeonsook Shin, Alexa Semonche, and Weijian Yang for technical assistance.

The authors declare no competing financial interests.

Correspondence should be addressed to Dr Mahesh Karnani, Department of Biological Sciences, Columbia University, 901 NWC Building, MC4822, 550 West 120th Street, New York, NY 10027. E-mail: miikael.mmk@gmail.com. DOI:10.1523/JNEUROSCI.3646-15.2016

Copyright $\odot 2016$ the authors $\quad 0270-6474 / 16 / 363471-10 \$ 15.00 / 0$
}

Members of the SOM, PV, and chandelier cell populations mediate a broad blanket-like inhibition of most if not all PCs within their axonal arbors (Fino and Yuste, 2011; Packer and Yuste, 2011; Karnani et al., 2014; Inan et al., 2013). This widespread inhibition, in principle, should suppress the propagation of excitatory activity in neocortex. In fact, because PV and SOM are activated specifically with fast and slow inputs, and relay fast and slow inhibition, it seems as if the interneuron population was selectively designed to block both fast and slow excitatory activity.

How can cortical neurons become activated if they are under the control of these inhibitory blankets? One solution is by disinhibition, i.e., the selective removal of this blanket inhibition. Indeed, inhibitory connectivity among SOM, VIP, and PV populations has recently been shown to form specific disinhibitory motifs, most importantly through the inhibitory connection from VIPs to SOMs (Lee et al., 2013; Pfeffer et al., 2013; Pi et al., 2013; Fu et al., 2014; Zhang et al., 2014). However, little is known about the fine structure of $\mathrm{PC}$ disinhibition through the $\mathrm{VIP} \rightarrow \mathrm{SOM} \rightarrow \mathrm{PC}$ circuit, although recent evidence suggests a spatially restricted mode of action for this circuit that may be related to "the spotlight of attention" (Zhang et al., 2014). This facilitation of visual responses is enhanced during locomotion (Fu et al., 2014). Reconstructions of VIPs show many 
double bouquet-like axons (Kawaguchi and Kubota, 1996; Bayraktar et al., 2000; Tahvildari et al., 2012; Lee et al., 2013), consistent with horizontally local output. However, individual neuron activation experiments necessary to directly measure the spatial extent of disinhibition mediated by a VIP cell have not been performed.

In this study, we show with intracellular recordings and optogenetics in neocortical layer $2 / 3$ that VIP activation can override lateral disynaptic inhibition between PCs in slices. In vivo, pairwise correlations between layer 2/3 VIP and PC activity were more local than those among PCs and two-photon activation of single VIPs created disinhibitory "holes" of increased visual responses during stimulusevoked activity. Our data indicate that VIPs can make $\sim 240 \mu \mathrm{m}$ diameter holes in the blanket of inhibition mediated by SOMs (Fino and Yuste, 2011; Karnani et al., 2014).

\section{Materials and Methods}

Animals. Animal handling and experimentation were performed in accordance with the U.S. National Institutes of Health and Columbia University Institutional Animal Care and Use Committee guidelines. Animals of both sexes were used and were housed in a controlled environment on a $12 \mathrm{~h}$ light/dark cycle with food and water ad libitum. VIP-cre (stock no. 010908), SOM-cre (stock no. 013044), SOM-GFP(GIN; stock no. 003718) and LSL-tdTomato (LSL-TOM, Ai14, stock no. 007908) mice were obtained from The Jackson Laboratory and crossbred to yield VIP-cre::LSL-TOM and SOM-cre::LSL-TOM. For results in Figure 2, $C$ and D, VIP-cre::LSL-TOM was further crossed with SOM-GFP(GIN) to yield VIP-cre::LSL-TOM::SOM-GFP(GIN).

Surgery: virus injections. Three to 4 weeks before the experiments VIP-cre::LSL-TOM mice were injected stereotactically with AAV1-synGCaMP6s (see Fig. 3) or a 1:3 mixture of AAV1-syn-GCaMP6s and AAV5-DIO-C1V1(E162T)-p2A-EYFP (see Figs. 6, 7) for in vivo experiments, and VIP-cre::LSL-TOM mice were injected with AAV5-DIOC1V1(E162T)-p2A-EYFP (see Fig. 5) or AAV5-DIO-ChETA-EYFP and SOM-cre::LSL-TOM mice with AAV5-FLEX-ArchT-GFP for slice experiments (Fig. 1). All viruses were obtained from the University of North Carolina vector core. For surgery, mice were anesthetized with isoflurane, the scalp was infiltrated with lidocaine, and a $0.1 \times 0.1 \mathrm{~mm}$ craniotomy was drilled for primary visual cortex (V1) at $2.5 \mathrm{~mm}$ lateral from lambda in the left hemisphere or for primary somatosensory (S1) at bregma $-0.5 \mathrm{~mm}, 3.0 \mathrm{~mm}$ lateral in the right hemisphere. An injection needle was slowly lowered to $150-200 \mu \mathrm{m}$ below the pial surface and $500-1000 \mathrm{nl}$ of virus was injected at a rate of $80 \mathrm{nl} / \mathrm{min}$. After removal of the injection needle, the scalp was sutured and animals received $5 \mathrm{mg} / \mathrm{kg}$ carprofen injections for $3 \mathrm{~d}$ as postoperative pain medication.

Surgery: in vivo experiments. Two weeks after viral delivery mice were anesthetized with isoflurane, the scalp infiltrated with lidocaine and a custom-made titanium head plate was attached to the skull using dental cement. A $2 \times 2 \mathrm{~mm}$ area of skull above the left V1 was thinned with a drill and covered with a glass coverslip attached with cyanoacrylate glue. The mice received single doses of $0.6 \mathrm{mg} / \mathrm{kg}$ dexamethasone and $5 \mathrm{mg} / \mathrm{kg}$ enrofloxacin, as well as $5 \mathrm{mg} / \mathrm{kg}$ carprofen injections for $3 \mathrm{~d}$ as postoperative pain and anti-inflammatory medication, and over the following week were briefly trained for head-fixed awake experiments in two to three sessions of increasing length on the experimental running-wheel apparatus.

For experiments in Figure 4, mice were anesthetized with isoflurane and a titanium head plate cemented over V1. The skull above V1 was removed with a dental drill. For bulk loading of cortical neurons, Oregon Green Bapta-1 AM (OGB-1 AM, Invitrogen) was first mixed with $4 \mu \mathrm{l}$ pluronic acid (20\% in DMSO) and further diluted in $35 \mu$ l dye buffer (150 $\mathrm{mm} \mathrm{NaCl}, 2.5 \mathrm{~mm} \mathrm{KCl}$, and $10 \mathrm{~mm}$ HEPES, pH 7.4). Sulforhodamine 101 (SR101; $50 \mu \mathrm{M}$, Invitrogen) was added to the solution to label astrocytes. The dye was slowly pressure-injected into the left visual cortex at a depth of $150-200 \mu \mathrm{m}$ at $30^{\circ}$ angle with a micropipette $(1-2 \mu \mathrm{m}$ tip opening) using Picospritzer II (10 psi, $8 \mathrm{~min}$ ) under visual control of two-photon imaging $(10 \times$ water-immersion objective, 0.5 NA Olympus). After the injections, the exposed cortex was covered with agarose and a glass coverslip, to minimize movement during imaging. We waited
30-90 min to ensure dye uptake across a large number of cells before starting the experiment.

In vivo two-photon $\mathrm{Ca}^{2+}$ imaging and $\mathrm{ClV} 1$ photostimulation. On the day of the experiment the P60-P120 mouse was imaged in a dark room for 2-3 $\mathrm{h}$ head-fixed on a running disk allowing the animal to move or remain stationary ad libitum. Throughout imaging sessions, we recorded the movement of the running disk via a custom-built infrared optical mouse apparatus to distinguish between movement and stationary epochs.

Alternatively for some experiments in Figures 4, 6, and 7 the animals were lightly anesthetized with isoflurane $(0.6-1.1 \%)$ and kept on a $37^{\circ} \mathrm{C}$ warming plate during the experiment. Changes in GCaMP6s or OGB-1 fluorescence were imaged with a Two-photon Moveable Objective Microscope (Sutter) and a mode-locked Ti:sapphire laser (Chameleon Vision II, Coherent) at $950 \mathrm{~nm}$ through a $25 \times$ (1.05 NA, Olympus) water-immersion objective at $4.07 \mathrm{fps}$ with $512 \times 512$ pixel resolution using Mscan software (Sutter; see experiments in Figs. 3, 4) or with a Prairie Ultima microscope (Bruker) through a $20 \times(0.95$ NA, Olympus) water-immersion objective at $4.08 \mathrm{fps}$ with $256 \times 256$ pixel resolution using Prairieview software (Bruker; see experiments in Figs. 6, 7). Images were obtained with a 535/50 and 610/75 nm bandpass emission filters for the green and red channels, respectively. The excitation light source for single-cell activation was a femtosecond-pulsed $1064 \mathrm{~nm}$ laser (Fianium) or a $1040 \mathrm{~nm}$ Spirit laser (Spectra-Physics) operated at $1 \mathrm{MHz}$ repetition rate. After passing through galvanometer mirrors, the excitation beam was coupled to the imaging path with a $1030 \mathrm{~nm}$ low-pass dichroic as by Packer et al. (2015). Excitation laser output was controlled with a pockels cell (Conoptics) to deliver between 20 and $50 \mathrm{~mW}$ on sample.

Visual stimuli were generated using MATLAB (MathWorks) Psychophysics toolbox and displayed on an LCD monitor (19 inches, $60 \mathrm{~Hz}$ refresh rate) positioned $15 \mathrm{~cm}$ from the right eye. The presentation of visual stimuli was synchronized with image acquisition and single-cell activation using a custom routine written in MATLAB.

In Figure 4, mice were presented with sequences of natural images or full-field square-wave gratings against a mean luminance gray background, presented with temporal frequency of $1.5 \mathrm{~Hz}$, spatial frequency of 0.04 cycles $/{ }^{\circ}$ and $100 \%$ contrast. Gratings were presented in 12 directions (separated by $30^{\circ}$ ) in a pseudorandom order for either 0.15 or $0.42 \mathrm{~s}$, followed by $3-5 \mathrm{~s}$ of mean luminescence gray screen (15-20 repetitions). In Figure 6, gratings had the same parameters except that they were presented for $0.6 \mathrm{~s}$ and three directions separated by $60^{\circ}$ were used in a pseudorandom order interlaced with $15 \mathrm{~s}$ of mean luminescence gray screen. Stimuli in each direction were repeated 100 times without and 100 times with single-cell activation during each experiment.

Calcium imaging analysis. Motion artifacts and drifts in the imaging plane were corrected using TurboReg plug-in in ImageJ (NIH). Initial image processing was performed using custom-written software in MATLAB. Cell outlines were drawn manually. Mean intensity within each region-of-interest (ROI) was used for $r a w \Delta F / F$ by comparing to the previous $10 \mathrm{~s}$. The $\Delta \mathrm{F} / \mathrm{F}$ used for analysis was obtained by subtracting from each cell's raw $\Delta F / F$ its neuropil signal (defined as the $0.7 \times$ raw $\Delta F / F$ of the extracellular space between the 300th and 500th closest pixels that did not include another ROI). Pairwise correlations were computed using Pearson's correlation. For data in Figures $6 B-F$ and 7, each differently oriented grating was defined as a separate experiment. Locomotion epochs were defined as the time when the mouse moved $>1 \mathrm{~cm} / \mathrm{s}(20$ optical mouse pulses/frame) along with the $5 \mathrm{~s}$ before and after these bouts, because locomotion and its onset and offset are known to modulate V1 neurons (Fu et al., 2014). In addition to the active cell cutoff of mean +1.5 SD used in Figures 3, $E, G$, and $I$, and $4, F$ and $G$, we also tried mean $+0.3,0.5,1.0$, and $2.0 \mathrm{SD}$, of which the 1.5 and $2.0 \mathrm{SD}$ worked similarly, whereas results with the lower cutoffs did not produce meaningful results (data not shown).

Preparation of acute slices. Coronal brain slices from P21-P180 animals were prepared after instant cervical dislocation and decapitation. The brain was rapidly dissected and cooled in continuously gassed $\left(95 \% \mathrm{O}_{2}\right.$ and $5 \%$ $\mathrm{CO}_{2}$ ), icy cutting solution containing the following (in mM): $90 \mathrm{~N}$-methyl-D-glucamine, $20 \mathrm{HEPES}, 110 \mathrm{HCl}, 3 \mathrm{KCl}, 10 \mathrm{MgCl}_{2}, 0.5 \mathrm{CaCl}_{2}, 1.1$ $\mathrm{NaH}_{2} \mathrm{PO}_{4}, 25 \mathrm{NaHCO}_{3}, 3$ pyruvic acid, 10 ascorbic acid, and 25 D-glucose. Three-hundred-micrometer-thick coronal brain slices were cut on a vi- 
A

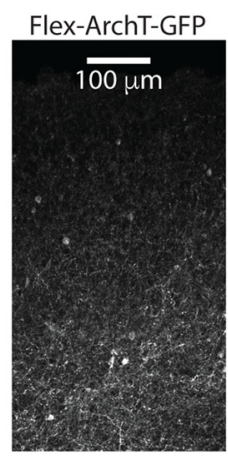

B

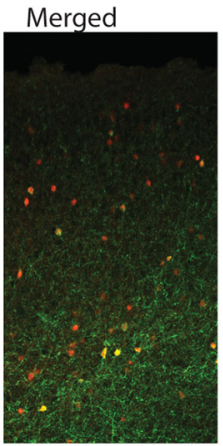

E

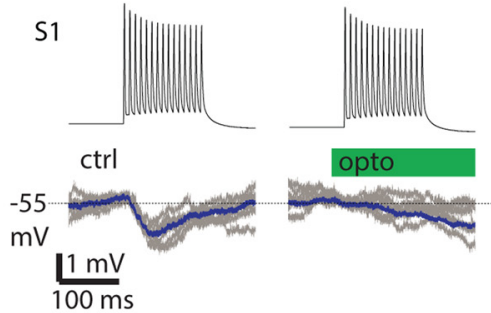

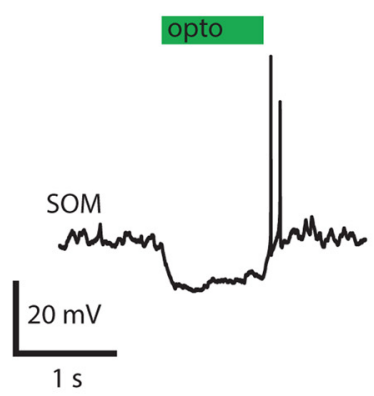

C

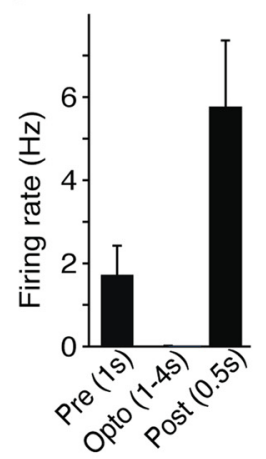

G

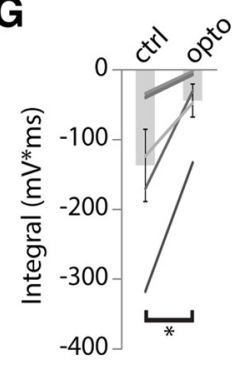

H

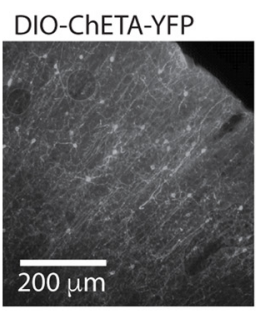

K

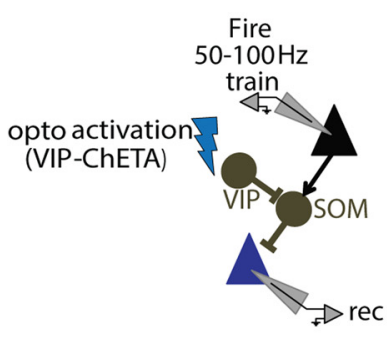

L

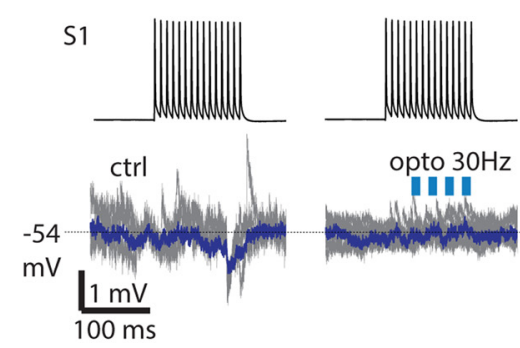

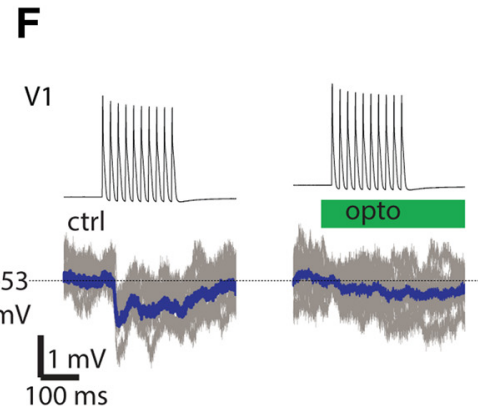

I

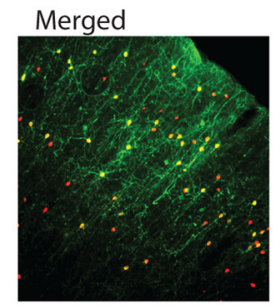

J
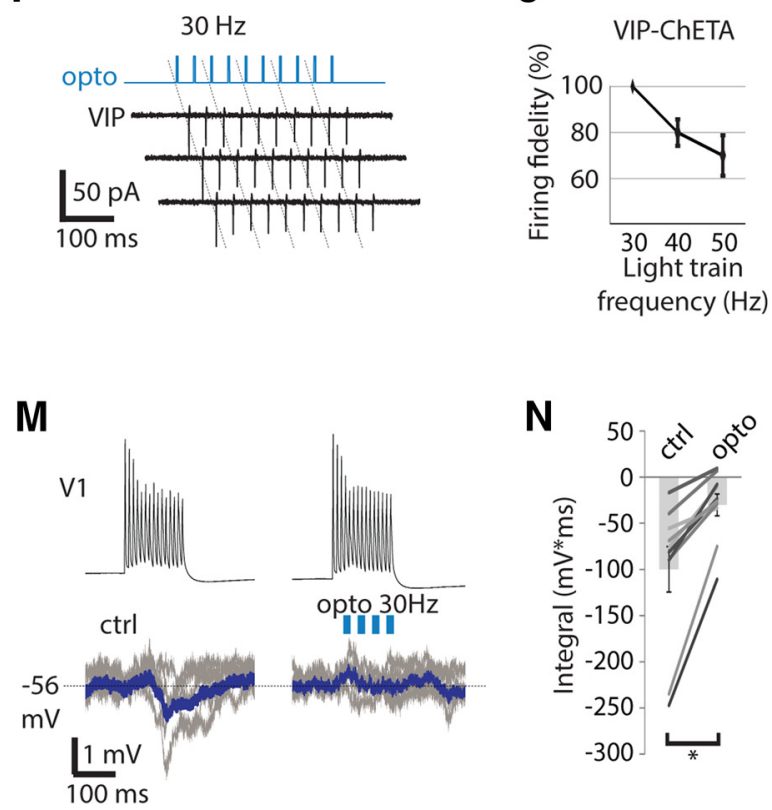

N

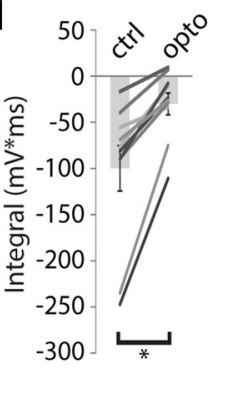

Figure 1. VIP activation vetoes SOM-mediated lateral inhibition. $A$, Fluorescent micrographs of tdTomato and ArchT-GFP expression in V1 of SOM-cre:::LSL-TOM mouse injected with AAV-flex-ArchT-GFP. B, Representative whole-cell current-clamp trace from ArchT-expressing SOM cell during application of green light pulse. $C$, Quantified spontaneous firing rates from $n=5$ SOM cells recorded as in $\boldsymbol{B}$. D. Schematic of experimental paradigm where two PCs were recorded in current-clamp and one of them was forced to fire a $50-100 \mathrm{~Hz}$ AP train, during which the other cell received disynaptic inhibition. ArchT in SOMs was used to inhibit SOMs. E, Example recording from S1. The top traces are presynaptic APs and blue traces below them are average across trials from the postsynaptic $P C$ (with individual trials superimposed in gray). Green bar indicates interleaved trials when the light was on to inhibit SOM firing. $\boldsymbol{F}$, Example recording from V1, same notation as $\boldsymbol{E}$. G, Quantified average IPSP integral across 5 experiments as in $\mathrm{E}, \mathrm{F}(n=2$ from V1, $n=3$ from $\mathrm{S} 1)$. ${ }^{*} p=0.037$. $\boldsymbol{H}$, Fluorescent micrographs of tdTomato and ChETA-YFP expression in V1 of VIP-cre::TOM mouse injected with AAV-DI0-ChETA-YFP. I, Representative cell-attached recordings across three trials from a VIP cell expressing ChETA during application of $30 \mathrm{~Hz}$ blue light pulse trains. J, Firing fidelity across light train frequencies from four VIP cells recorded as in $I$. For all frequencies, pulse duration was $3 \mathrm{~ms}$. $\boldsymbol{K}$, Schematic of experimental paradigm as in $\boldsymbol{D}$ except with an excitatory opsin (ChETA) in VIPs. $\boldsymbol{L}$, Example recordings from S1 similar to $\boldsymbol{E}$. Blue pulses indicate interleaved trials when light was on to activate VIP firing. $\boldsymbol{M}$, Example recording from V1, same notation as $\boldsymbol{L}$. $\boldsymbol{N}$, Quantified average IPSP integral across 10 experiments as in $\boldsymbol{L}$ and $\boldsymbol{M}$ $(n=5$ for both $\mathrm{V} 1$ and $\mathrm{S} 1) .{ }^{*} p=0.0009$. 
A
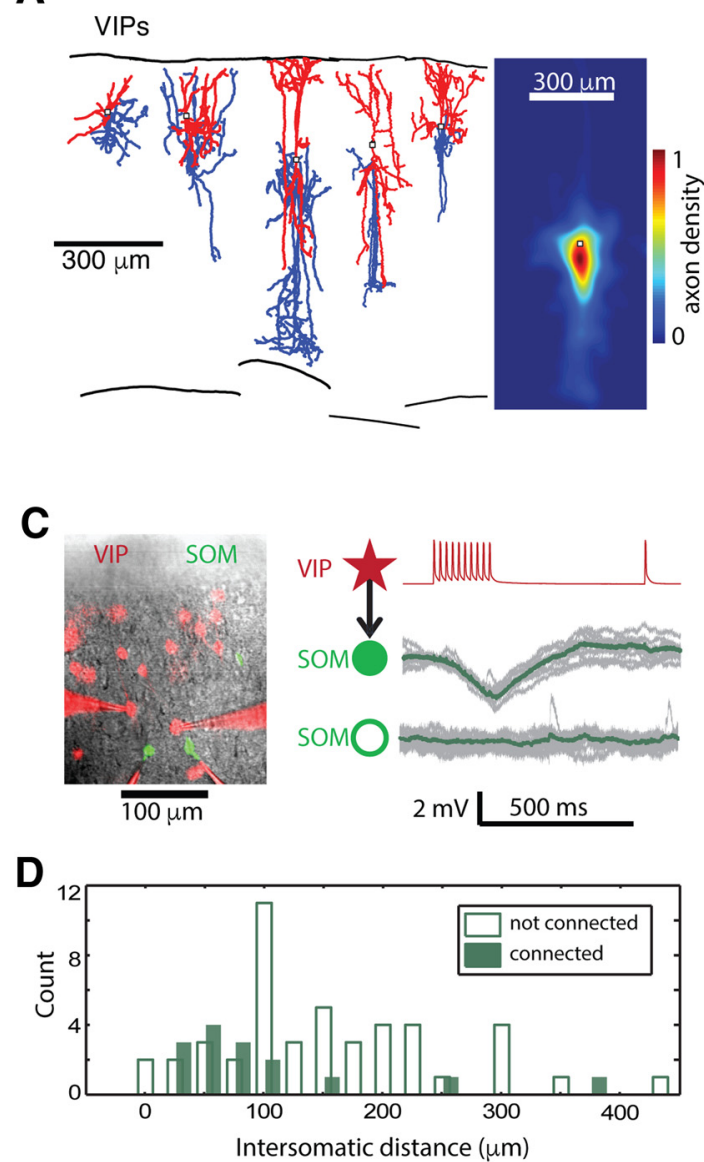

B

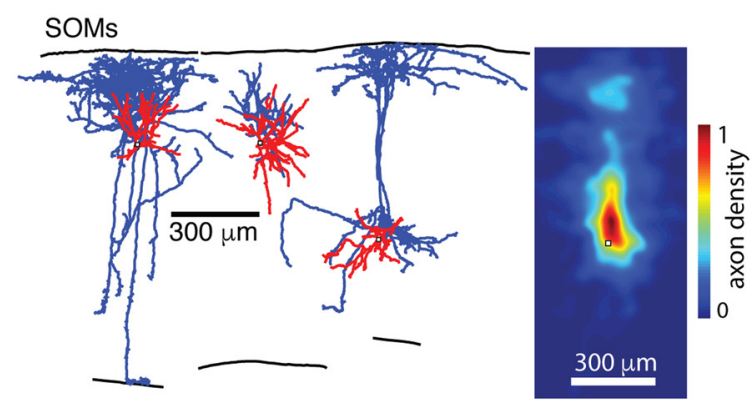

$\mathbf{E}$

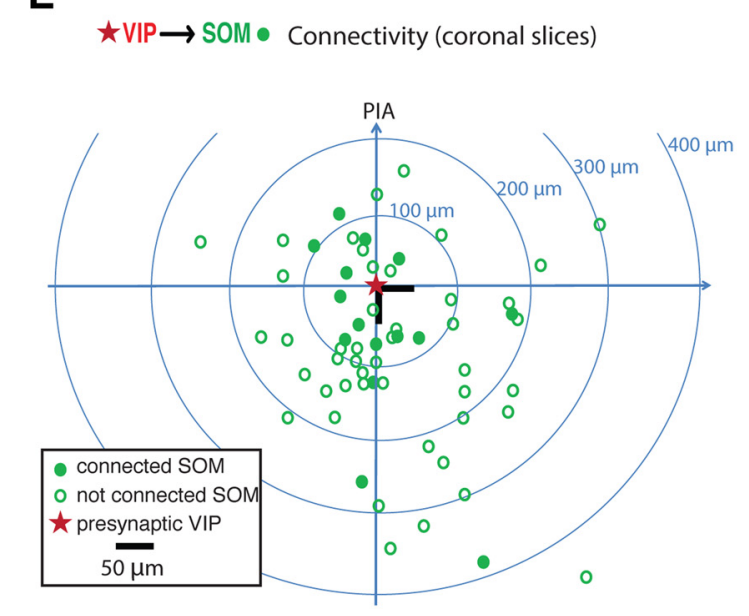

Figure 2. VIP axons are local, and vertical VIP $\rightarrow$ SOM connectivity is local. $A$, Examples of VIP cell morphology, somata denoted by white boxes, axons in blue and dendrites in red. Right, Average axon density plots for $n=19$ VIPs aligned by somata (white square). $\boldsymbol{B}$, Examples of SOM cell morphology, somata denoted by white boxes, axons in blue and dendrites in red. Right, Average axon density plots for $n=8$ SOMs aligned by somata (white square). C, Left, Representative fluorescent/oblique contrast micrograph of a VIP-cre::LSL-TOM::SOM-GFP(GIN) slice with two SOMs and two VIPs being recorded with patch pipettes filled with a red dye. Right, Representative traces of presynaptic spike train in VIP (top, red star), postsynaptic response in a connected SOM (middle) and a not connected SOM (bottom). Gray traces are individual trials and green traces their average. $\boldsymbol{D}$, Distance distribution of VIP $\rightarrow$ SOM connections, as well as not connected cells. Distributions are significantly different; connected $112 \pm 25 \mu \mathrm{m}, n=15$, and not connected $163 \pm 14 \mu \mathrm{m}, n=46 ; p=0.01$ by rank sum test. $\boldsymbol{E}$, Relative locations of connected and not connected VIP $\rightarrow$ SOM pairs recorded in coronal slices from $\mathrm{V} 1$.

bratome (Microm) and allowed to recover for $5-15 \mathrm{~min}$ at $37^{\circ} \mathrm{C}$ in cutting solution, followed by $45-55 \mathrm{~min}$ at $37^{\circ} \mathrm{C}$ in artificial CSF (ACSF) containing the following (in mM): $126 \mathrm{NaCl}, 3 \mathrm{KCl}, 2 \mathrm{MgSO}_{4}, 2 \mathrm{CaCl}_{2}, 1.1 \mathrm{NaH}_{2} \mathrm{PO}_{4}, 26$ $\mathrm{NaHCO}_{3}, 0.1$ pyruvic acid, 0.5 L-glutamine, 0.4 ascorbic acid, and 25 D-glucose, continuously gassed with $95 \% \mathrm{O}_{2}$ and $5 \% \mathrm{CO}_{2}$.

Slice electrophysiology. Patch-clamp recordings were performed in a submerged chamber with $5-10 \mathrm{ml} / \mathrm{min}$ superfusion with ACSF, continuously gassed with $95 \% \mathrm{O}_{2}$ and $5 \% \mathrm{CO}_{2}$. Four to $8 \mathrm{M} \Omega$ patch pipettes were filled with intracellular solution containing the following (in $\mathrm{mM}$ ): $130 \mathrm{~K}$-gluconate, $5 \mathrm{NaCl}, 2 \mathrm{MgSO}_{2}$, 10 HEPES, 0.1 EGTA, $4 \mathrm{Mg}$-ATP, 0.4 Na-GTP, 7 phosphocreatine, 2 pyruvic acid, 0.1 AlexaFluor 594, 0.2\% biocytin, and $\sim 10 \mathrm{~mm} \mathrm{KOH}$ (to set $\mathrm{pH}$ to 7.3 ). Whole-cell recordings were not analyzed if the access resistance was $>25 \mathrm{M} \Omega$. Voltage and current recordings were sampled at $10 \mathrm{kHz}$ and low-pass filtered at $4 \mathrm{kHz}$ with MultiClamp 700B amplifiers and acquired in LabView with custom software. ArchT was stimulated with green light from a mercury lamp through a TRITC-filter cube and ChETA with blue light through a FITC filter cube. Timing was controlled with a shutter (Uniblitz). Patch-clamp data were analyzed with custom routines in MATLAB.

Immunohistochemistry. Mice were overdosed with ketamine/xylazine (100 and $10 \mathrm{mg} / \mathrm{kg}$, respectively) and transcardially perfused with $4 \%$ PFA. Brains were postfixed for $24 \mathrm{~h}$. Coronal brain slices were sectioned at $40 \mu \mathrm{m}$ using a cryostat. Sections were blocked in PBS with $0.5 \%$ Triton $\mathrm{X}-100$ and $1 \%$ bovine serum albumin (blocking solution) for $1 \mathrm{~h}$, incubated with rabbit anti-GFP (1:500; Life Technologies) overnight, washed, incubated with Cy2-conjugated donkey anti-goat (1:500; Jackson ImmunoResearch) for $3.5 \mathrm{~h}$, washed, and mounted. Antibodies were applied in PBS with $0.3 \%$ Triton X-100 and $1 \%$ BSA. Confocal micrographs were merged in ImageJ.

Biocytin histochemistry and reconstructions. At the end of slice recordings, slices were fixed and kept overnight in $4 \%$ paraformaldehyde in 0.1 $\mathrm{M}$ phosphate buffer $(\mathrm{PB})$ at $4^{\circ} \mathrm{C}$. The slices were then rinsed in $\mathrm{PB}$, placed in $30 \%$ sucrose for $2 \mathrm{~h}$, and then frozen on dry ice in tissue freezing medium and stored at $-80^{\circ} \mathrm{C}$. After defrosting the tissue freezing medium was removed by rinsing in $\mathrm{PB}$ and slices were kept in $1 \%$ hydrogen peroxide in $\mathrm{PB}$ for $30 \mathrm{~min}$ on the shaker and then rinsed twice in $0.02 \mathrm{M}$ potassium phosphate saline (KPBS) for $20 \mathrm{~min}$ on the shaker. The slices were then kept overnight on the shaker in avidin-biotin-peroxidase complex. The slices were then rinsed three times in $0.02 \mathrm{M} \mathrm{KPBS}$ for $20 \mathrm{~min}$ each on the shaker. Each slice was then placed in $0.7 \mathrm{mg} / \mathrm{ml}$ diaminobenzidine, $0.2 \mathrm{mg} / \mathrm{ml}$ urea hydrogen peroxide, $0.06 \mathrm{M}$ Tris buffer in KPBS until the slice turned light brown, then rinsed in KPBS, and mounted using crystal mount. Successfully filled and stained neurons were then reconstructed using Neurolucida software (MicroBrightField) with a $\times 100$ oil objective on an Olympus BX51 upright light microscope. Reconstructions were analyzed with custom routines in MATLAB.

Statistics. All data are shown as mean \pm SEM unless stated otherwise. Statistical significance was determined by unpaired Student's $t$ tests unless stated otherwise. All statistics were performed using statistical functions in MATLAB or Excel. 
A
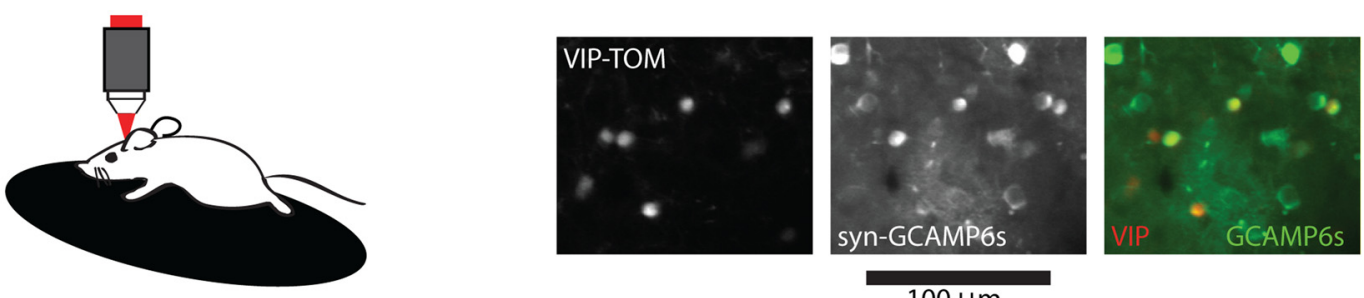

$100 \mu \mathrm{m}$
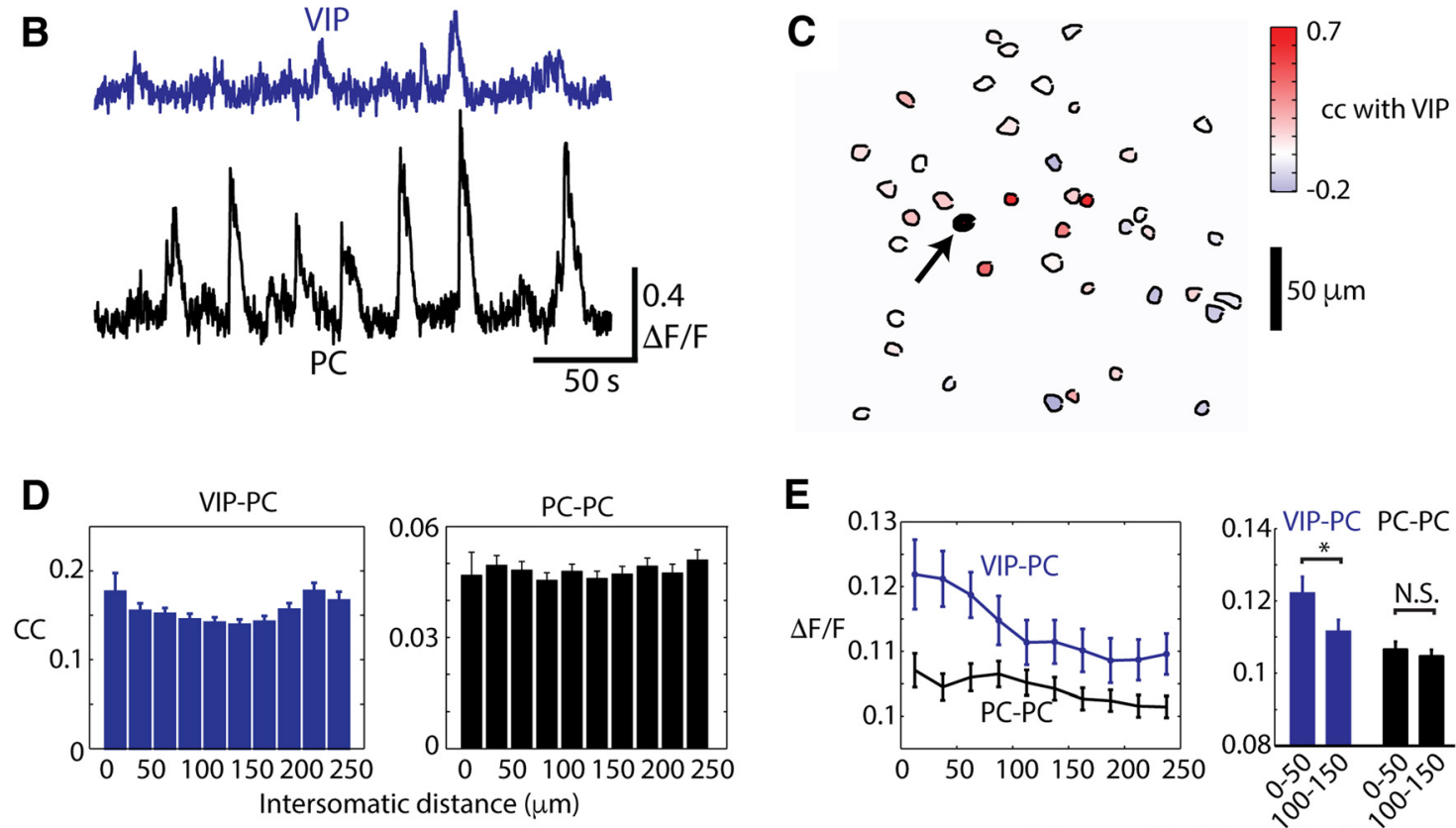

Intersomatic distance $(\mu \mathrm{m})$
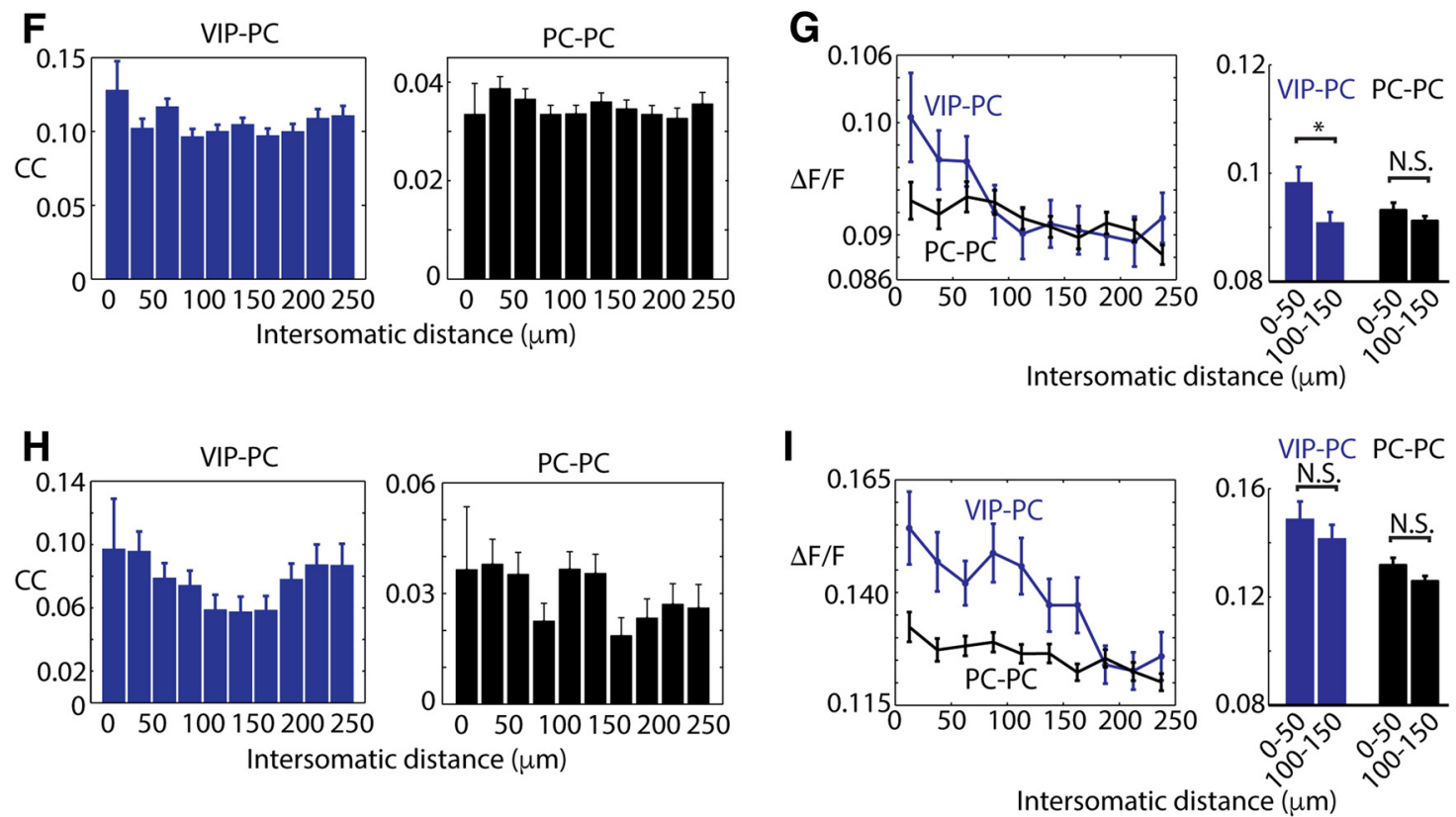

Figure 3. Spontaneous correlations between VIPs and putative PCs are local. $A$, Schematic of experiment (left) and two-photon fluorescence micrographs of syn-GCAMP6s and TdTomato expression in V1 of a VIP-cre::TOM mouse. $\boldsymbol{B}$, Example traces of activity in a VIP and a putative PC from the same field-of-view. $\boldsymbol{C}$, Example field-of-view with cells colored according to their pairwise correlation coefficient with the VIP cell marked by the arrow. D, Left, Correlations between VIPs and putative PCs (all non-VIP cells were defined as PCs because they form the vast majority of non-VIP L2/3 cells) as a function of intersomatic distance quantified across 11 experiments containing a total of 68 VIPs. Right, Correlations between PCs from same experiments. E, Left, GCaMP6s fluorescence of cells in the imaged region during frames when VIP cells were active (blue) as a function of distance from the VIP cell, and the same quantification for PCs (black). Right, Comparison of data from left panel as indicated. ${ }^{*} p=0.005 ;$ N.S., $p=0.22$ by paired $t$ test. Data are from the same experiments as in $\boldsymbol{D}$. $\boldsymbol{F}$, Same data and analysis as $\boldsymbol{D}$ but only on stationary epochs. $\mathbf{G}$, Data from $\boldsymbol{F}$ analyzed as in $\boldsymbol{E}$. ${ }^{*} p=0.03 ;$ N.S., $p=0.24$. $\boldsymbol{H}$, Same data and analysis as $\boldsymbol{D}$ but only on locomotion epochs. $\boldsymbol{I}$, Data from $\boldsymbol{H}$ analyzed as in $\boldsymbol{E}$. N.S., $p>0.08$. 
A
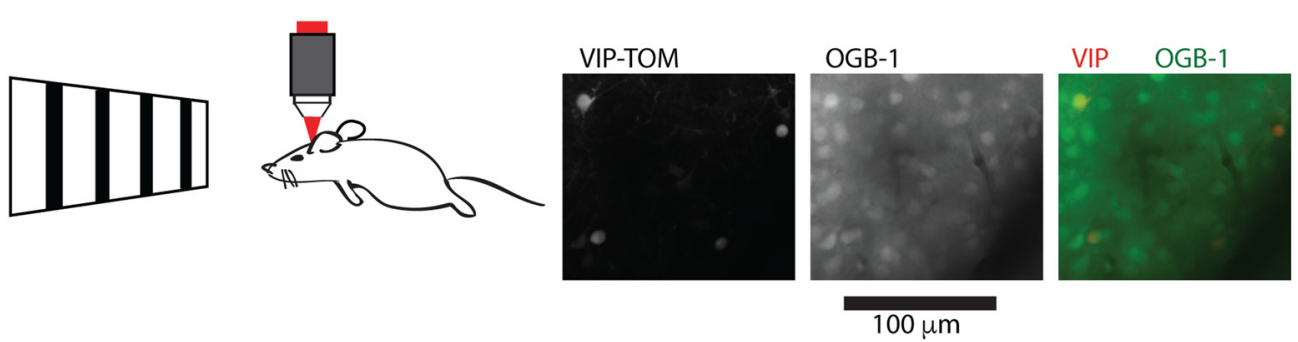

B
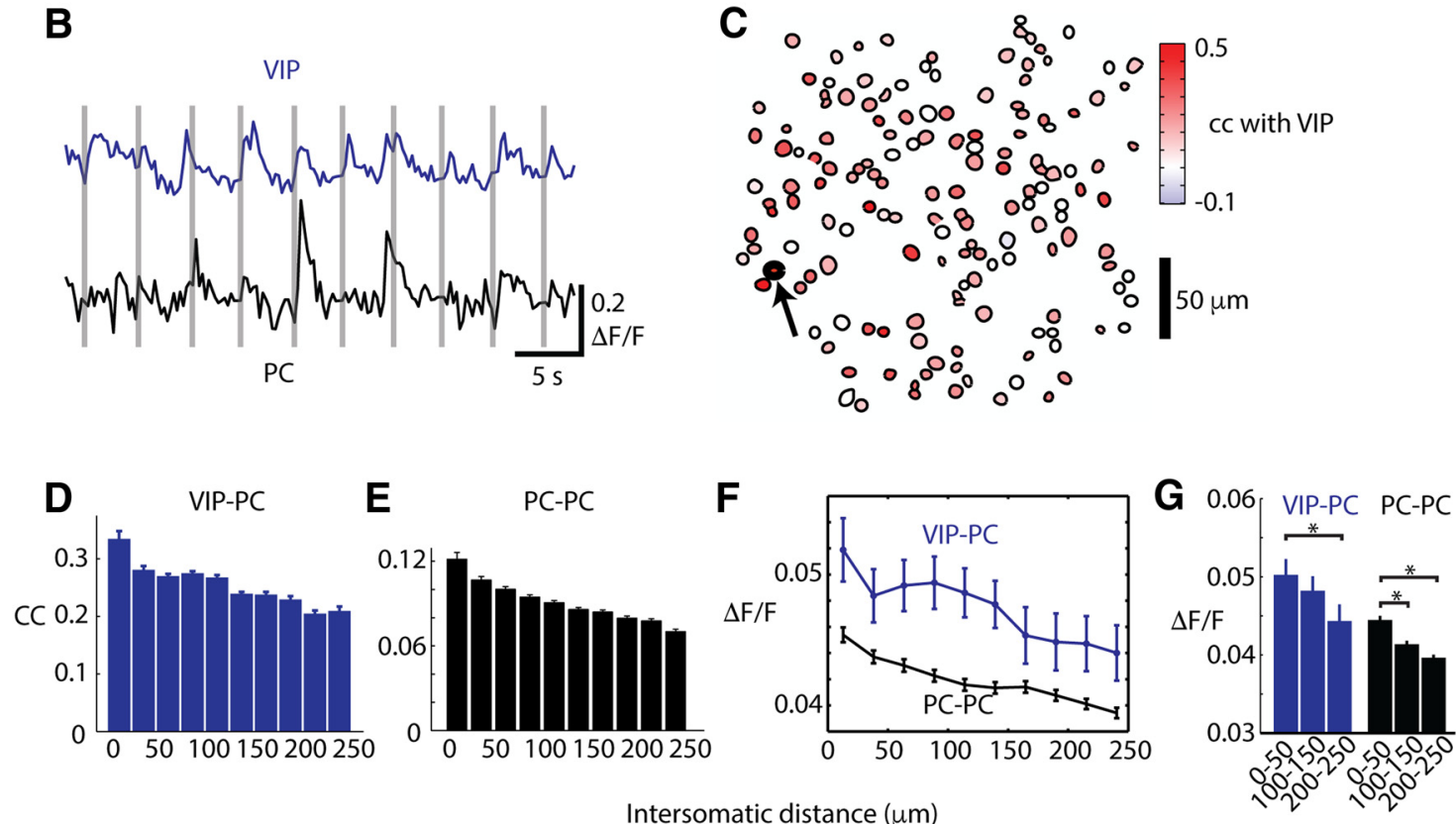

Intersomatic distance $(\mu \mathrm{m})$

Figure 4. Visual stimulus-evoked correlations between VIPs and putative PCs are local. $A$, Schematic of experiment (left) and two-photon fluorescence micrographs of OGB-1 and TdTomato in V1 of a VIP-cre::TOM mouse. $\boldsymbol{B}$, Example traces of activity in a VIP and a putative $\mathrm{PC}$ from the same field-of-view. Visual stimuli (drifting gratings or natural images presented for $150 \mathrm{~ms}$ ) denoted by gray bars. C, Example field-of-view with cells colored according to their pairwise correlation coefficient with the VIP cell marked by the arrow. D, Correlations between VIPs and putative PCs as a function of intersomatic distance quantified across five experiments from three mice containing a total of $18 \mathrm{VIPS}$. $\boldsymbol{E}$, Correlations between PCs from same experiments as in $\boldsymbol{D}$. $\boldsymbol{F}$, OGB-1 fluorescence of cells in the imaged region during frames when VIP cells were active (blue) as a function of distance from the VIP cell, and the same quantification for PCs (black). Data are from the same experiments as in $\boldsymbol{D}$ and $\boldsymbol{E}$. $\boldsymbol{G}$, Comparison of data from $\boldsymbol{F}$ as indicated. ${ }^{*} p<0.01$ by paired $t$ test.

\section{Results}

SOMs mediate lateral inhibition in brain slices and VIPs block it

To begin investigating the effective range of a single VIP, we first explored the mechanism by which VIPs can remove lateral inhibition in the neocortex. While many experiments are consistent with SOMs mediating frequency-dependent disynaptic inhibition (FDDI) between neighboring PCs, a cell-type-specific lossof-function experiment has not been performed (Kapfer et al., 2007; Silberberg and Markram, 2007; Murayama et al., 2009). To this end, we expressed the optogenetic neuronal silencer ArchT in SOMs using SOM-cre mice injected with AAV5-FLEX-ArchTGFP (Fig. $1 A-C$ ), and patched two nearby PCs in slices from these animals (Fig. 1D). When one PC fired a $70-100 \mathrm{~Hz}$ train of action potentials, the other PC was inhibited with an onset latency of $41 \pm 16 \mathrm{~ms}$ from the start of the train presumably by disynaptic inhibition (Fig. $1 D-F$ ). However, when we exposed the slice to green light during this time to inhibit SOMs, the disynaptic inhibition was blocked, confirming that SOMs mediate FDDI (Fig. 1D-G). These experiments were performed by alternating control and optogenetic trials in the same PC pairs.

To test whether VIPs can control FDDI through SOMs, we repeated the same experiment in tissue expressing the light- activated cation channel ChETA in VIPs (Fig. $1 H-J$ ). When we activated VIPs during the train of action potentials in one $\mathrm{PC}$, the FDDI in another nearby PC was blocked (Fig. $1 K, M$ ). The data in Figure 1 indicate that VIPs specialize in lateral disinhibition and can block FDDI by inhibiting SOMs. Through this mechanism, VIPs can control the lateral spread of excitation. We next went on to study how far a single VIP can project this effect.

\section{VIP axons are vertically narrow}

Previous anatomical data suggest that VIPs tend to have vertically elongated axons (Kawaguchi and Kubota, 1996; Bayraktar et al., 2000; Tahvildari et al., 2012; Lee et al., 2013). We tested this by reconstructing biocytin filled VIPs in coronal brain slices. VIP axons tended to descend away from the pia and were narrower than SOM or PV axons (Fig. 2A,B; vertical length, horizontal length, $n$ : VIPs: $440 \pm 53 \mu \mathrm{m}, 233 \pm 29 \mu \mathrm{m}, n=19$; SOMs: $756 \pm$ $85 \mu \mathrm{m}, 615 \pm 82 \mu \mathrm{m}, n=8$; PVs: $628 \pm 83 \mu \mathrm{m}, 649 \pm 122 \mu \mathrm{m}$, $n=7$ ). A horizontally narrow axon (Fig. $2 A-D$ ) may restrict the area of effect of a single VIP to a small cylindrical volume of cortex. Because VIPs mainly target SOMs (Lee et al., 2013; Pfeffer et al., 2013), which mediate promiscuous blanket-like inhibition of nearby PCs (Fino and Yuste, 2011), it is possible that the role of VIPs is to make spatially restricted holes in the blanket of inhibi- 
A

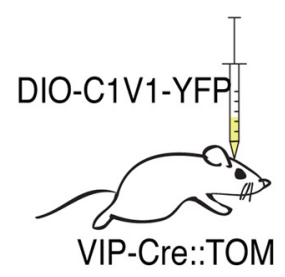

B

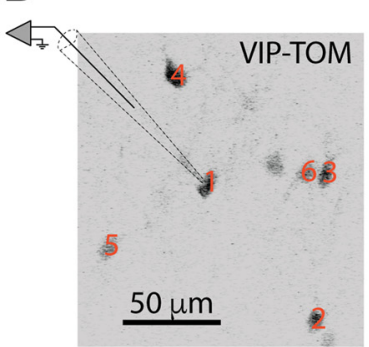

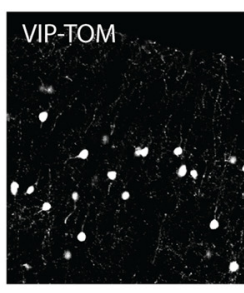
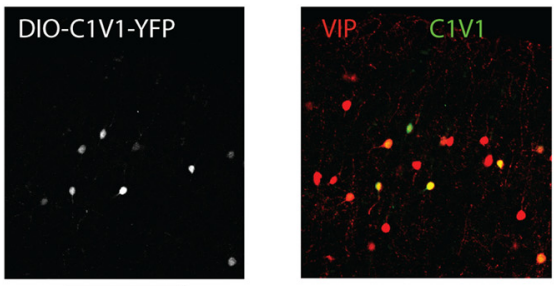

$100 \mu \mathrm{m}$

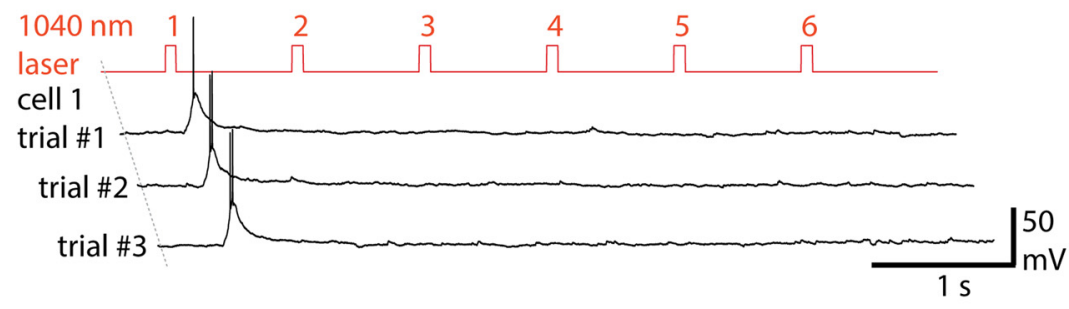

Figure 5. Individual VIP activation with two-photon optogenetics. $A$, Left, C1V1 was expressed in VIP cells in VIP-cre::TOM animals. Right, Confocal micrographs of DI0-C1V1-YFP expression in VIP-cre::TOM cells in fixed coronal sections. Scale bar applies for all panels. B, Spiral scan with $1040 \mathrm{~nm}$ two-photon laser over numbered targets corresponding to VIP-C1V1 cells. The recorded VIP \#1 was only activated when the spiral was targeted to that cell. Recordings in VIP-cre::TOM slices expressing DI0-C1V1-YFP.

tion (Karnani et al., 2014). This might serve attention (Harris and Thiele, 2011; Zhang et al., 2014). To start searching for these holes we assayed connectivity between VIPs and SOMs in tripletransgenic tissue (VIP-cre::LSL-TOM::SOM-GFP; Fig. 2C) using patch-clamp recordings in acute slices. We plotted distances to SOMs that were postsynaptic to VIPs (Fig. $2 D, E$ ). SOMs that were inhibited by VIPs were closer to the presynaptic VIP (112 \pm $25 \mu \mathrm{m}, n=15)$ than SOMs that were not connected (163 \pm 14 $\mu \mathrm{m}, n=46, p=0.01$, rank sum test). The connected SOMs also tended to be further away from the pia and vertically aligned with the presynaptic VIP (Fig. 2E), as expected from the axonal profile of VIPs. These results indicate that both the axonal morphology and spatial distribution of VIP $\rightarrow$ SOM connectivity allow VIPs to make holes in blanket inhibition.

\section{Local correlation of VIP-PC activity in vivo}

We then went on to study the spatial profile of VIP output in vivo with two-photon $\mathrm{Ca}^{2+}$ imaging. Using syn-GCAMP6s expressing VIP-cre::TOM mice we first observed correlations between spontaneous activity in L2/3 VIPs and other cells (mostly PCs) in awake head-fixed mice (Fig. $3 A, B$ ). Pairwise Pearson correlation coefficients between $\mathrm{Ca}^{2+}$ activity in VIPs and other cells tended to be higher at short intersomatic distances (Fig. $3 C, D$ ), whereas correlations between other cells were similar at all distances (Fig. 3D). To further test the distance dependence of activity near a VIP, we plotted the average $\mathrm{Ca}^{2+}$ signal in nearby cells in imaging frames where the VIP signal crossed a threshold of mean +1.5 SD (see Materials and Methods). We repeated this analysis by triggering on the other cells (mostly PCs). This analysis showed that spontaneous activity in VIPs is closely tied to activity in the other cells within a $50 \mu \mathrm{m}$ radius, whereas activity in PCs showed a weak distance dependence with nearby cells (Fig. $3 E)$. PC triggered $\Delta \mathrm{F} / \mathrm{F}$ decreased from $0.107 \pm 0.002$ at $0-50 \mu \mathrm{m}$ to $0.105 \pm 0.002$ at $100-150 \mu \mathrm{m}(p=0.22$, paired $t$ test $)$, whereas VIP triggered $\Delta \mathrm{F} / \mathrm{F}$ decreased from $0.122 \pm 0.005$ at $0-50 \mu \mathrm{m}$ to $0.111 \pm 0.003$ at $100-150 \mu \mathrm{m}(p=0.005)$.

Because VIPs tend to be activated during locomotion (Fu et al., 2014), we divided the awake data into periods when the animal was moving (locomotion) and periods when the ani- mal was still (stationary), and repeated the analyses (Fig. 3F$I$ ). The result was similar during stationary epochs (Fig. $3 F, G$; VIP triggered $\Delta \mathrm{F} / \mathrm{F}$ decreased from $0.098 \pm 0.003$ at $0-50 \mu \mathrm{m}$ to $0.091 \pm 0.002$ at $100-150 \mu \mathrm{m}, p=0.03$; PC triggered $\Delta \mathrm{F} / \mathrm{F}$ decreased from $0.093 \pm 0.002$ at $0-50 \mu \mathrm{m}$ to $0.091 \pm 0.001$ at 100-150 $\mu \mathrm{m}, p=0.24)$. However, despite a trend toward lower correlation with further away cells, the same quantification turned out not significant during locomotion epochs (Fig. $3 H, I$; VIP triggered $\Delta \mathrm{F} / \mathrm{F}$ decreased from $0.149 \pm 0.007$ at $0-50 \mu \mathrm{m}$ to $0.142 \pm 0.005$ at $100-150 \mu \mathrm{m}, p=0.09$; PC triggered $\Delta \mathrm{F} / \mathrm{F}$ decreased from $0.132 \pm 0.003$ at $0-50 \mu \mathrm{m}$ to $0.126 \pm 0.002$ at $100-150 \mu \mathrm{m}, p=0.33)$. Thus, the increased neuronal activity during locomotion seems to be less spatially structured around single VIPs.

To see whether the overall pattern in Figure 3, $D$ and $E$, repeated during visual processing, we presented $150 \mathrm{~ms}$ drifting gratings or natural images to drive activity in V1 of anesthetized (to eliminate eye movements) VIP-cre::TOM mice after loading $\mathrm{V} 1$ with the fast calcium indicator OGB-1 (Fig. $4 A, B$ ). We analyzed data from the stimulus frame and the following frame for the following analyses to focus on visual responses rather than background activity. Pairwise Pearson's correlation coefficients decreased with distance during visually evoked activity in VIP-PC pairs (Fig. 4C,D). PC-PC pairs showed a similar distance dependence (Fig. 4E) unlike during spontaneous activity (Fig. 3D). When we plotted activity of PCs as a function of distance from an active VIP (defined as +1.5 SD from mean as in Fig. $3 E$ ) we saw a distance-dependent decrease that started further away from the VIPs (Fig. 4F, G) than during spontaneous activity (Fig. 3D,E). PC-triggered activity in nearby cells was also significantly distance-dependent (Fig. $4 F, G$ ) unlike during spontaneous activity (Fig. 3D,E).

These results are consistent with VIPs disinhibiting a small nearby volume of cortex in vivo, during both spontaneous and visually evoked activity, but might equally arise from the nearby cells driving the VIPs. To isolate more cleanly the output of VIPs, we next stimulated a single VIP with optogenetics. 
A

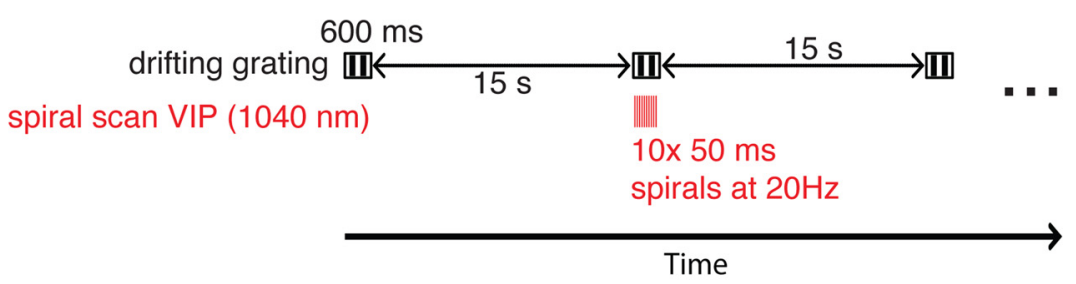

B

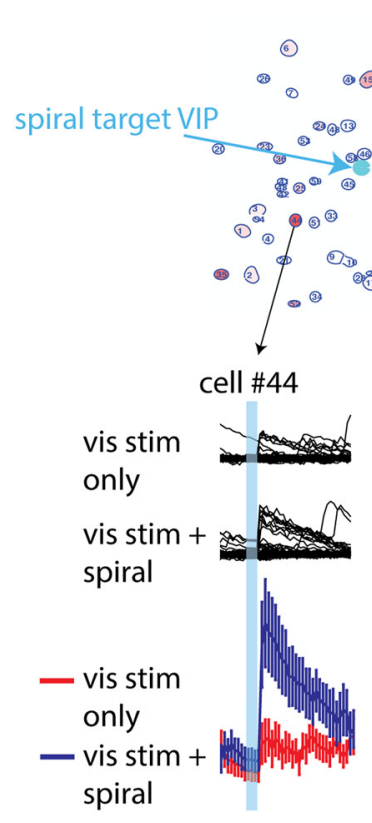

D

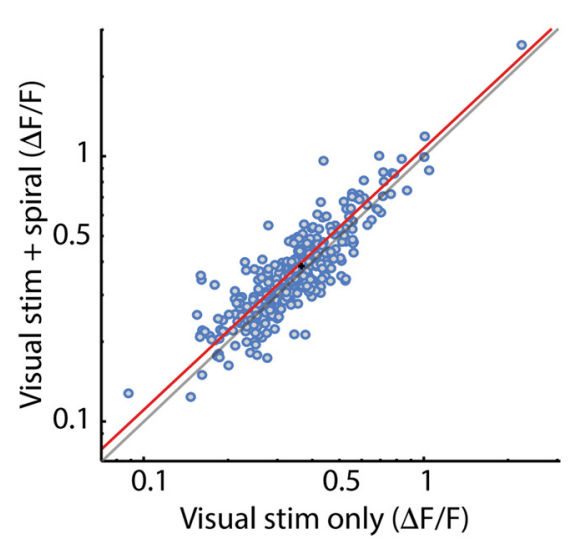

C

Anaesthetised
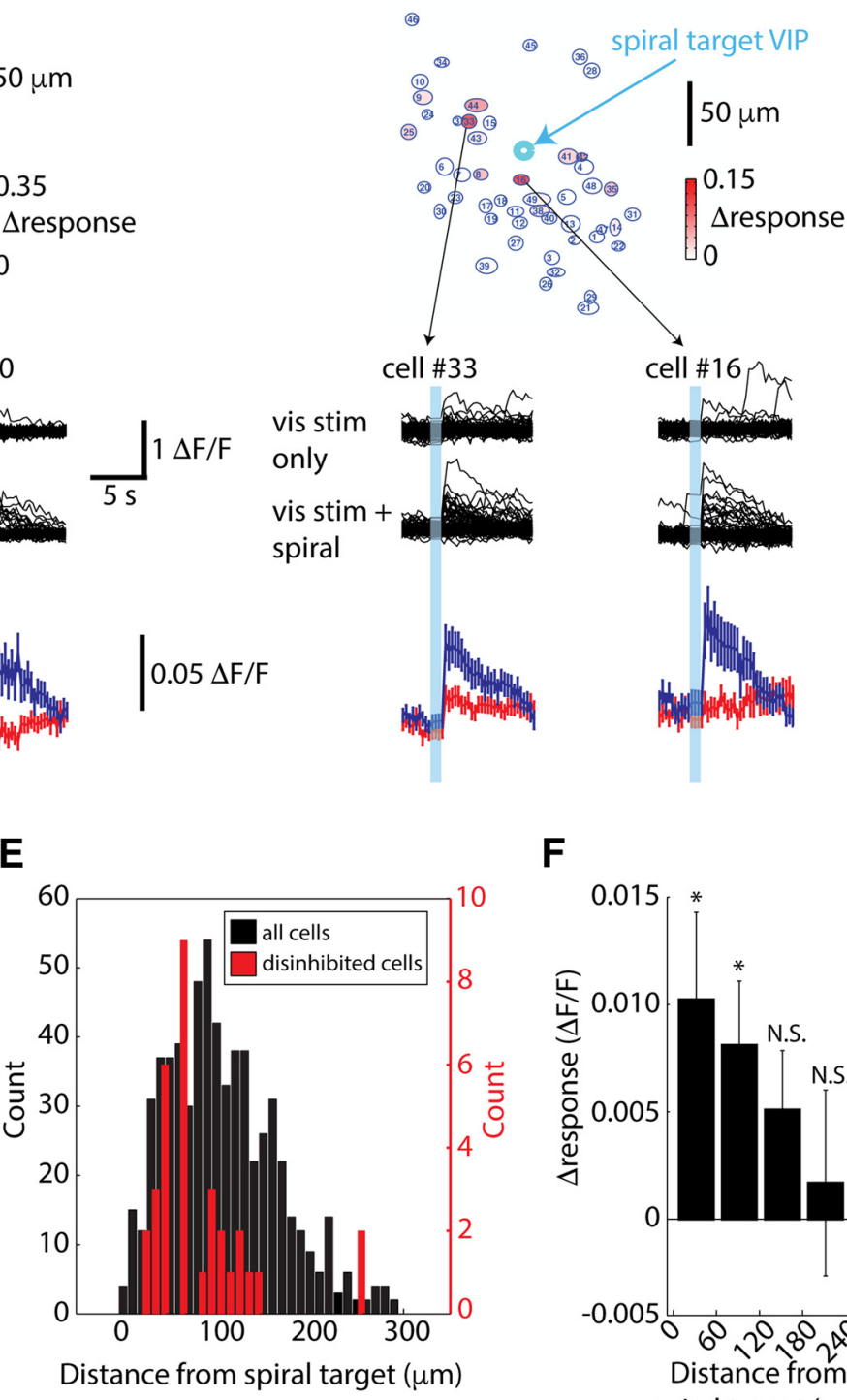

$\mathbf{F}$

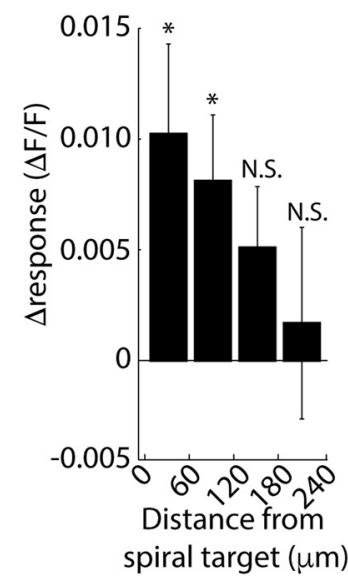

Figure 6. Individual VIP activation with spiral scan disinhibits visual responses of nearby $\mathrm{PCS} . A$, Schematic of experiment paradigm. $B, C, G C a M P 6$ imaging in vivo with simultaneous visual stimulation and spiral scan on a VIP-C1V1 cell in awake $(\boldsymbol{B})$ and anesthetized ( $\boldsymbol{C}$ mice. From each experiment, two disinhibited example cells are shown. The visual stimulus was a $60^{\circ}$ drifting grating in both examples. In the contour plots (top), cells are colored according to the extent of their disinhibition by the single VIP activation. $\boldsymbol{D}$, Scatter plot of data from awake mice only (12 experiments). Small black cross in the middle denotes mean \pm SEM. Red line is a linear fit to data and gray line is unity. $p=0.00003$ by paired ttest. $E$, Distribution of significantly (visual stimulus-evoked response changed by $>2 \times S D$ of ctrl data) disinhibited cells (total 33 cells) by distance from spiral target from 27 experiments from nine mice. $p=0.002$ by rank sum test. There were also six cells whose responses were significantly inhibited by the spiral. Because these were a minority, we did not analyze them further. $F$, Average spiral-induced change in visual responses by distance from spiral target. ${ }^{*} p<0.05$ and N.S., $p>0.05$ by $Z$ test against zero.

Two-photon optogenetic activation of individual VIP cells reveals a local disinhibitory effect in vivo

By expressing the two-photon addressable opsin C1V1 (Packer et al., 2012) in VIP-cre::TOM mice (using AAV5-DIO-C1V1-YFP; Fig. $5 A$ ) we were able to stimulate six of eight individual VIP cells patch-clamped in acute slices by scanning a $1040 \mathrm{~nm}$ laser $(20-50$ $\mathrm{mW}$ on the specimen) over the soma with a spiral pattern. Targeting the stimulation to other nearby VIPs did not excite the recorded VIP (Fig. 5B). We then repeated these spiral stimulations in vivo in VIP-cre::TOM mice expressing DIO-C1V1 and 

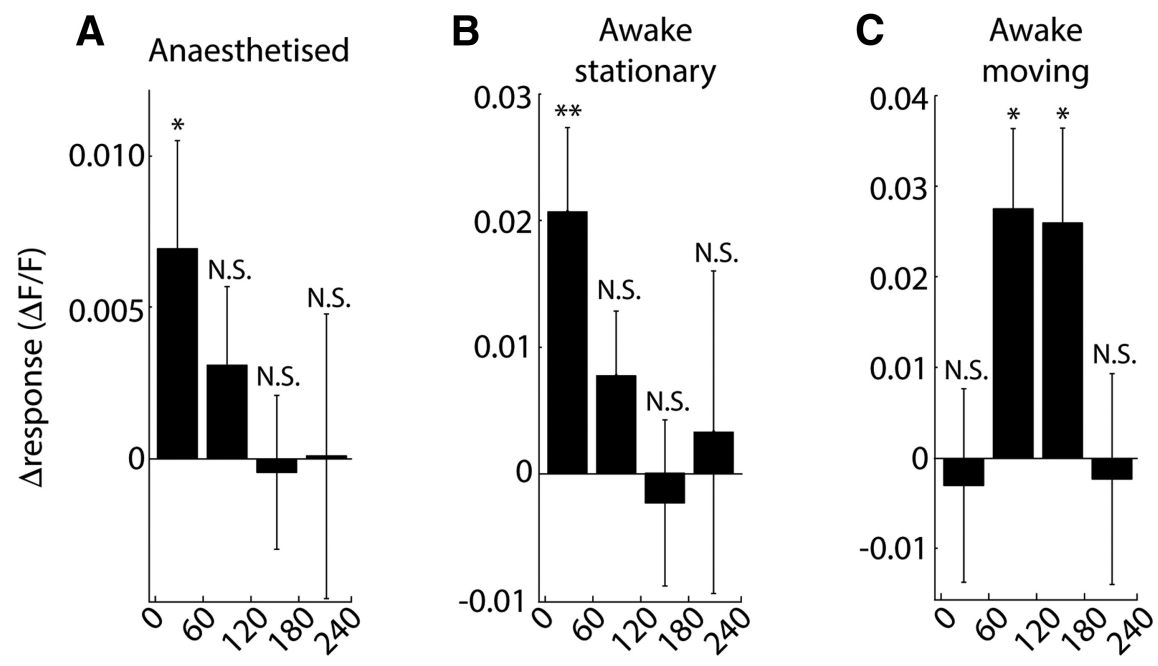

Distance from spiral target $(\mu \mathrm{m})$

Figure 7. Individual VIP activation induced visual response changes across behavioral states. $\boldsymbol{A}-\boldsymbol{C}$, Average spiral-induced change in visual responses by distance from spiral target in anesthetized animals $\left(\boldsymbol{A} ; n=15\right.$ experiments), awake stationary ( $\boldsymbol{B}_{\text {; }}$ $n=9$ experiments), and awake moving $\left(\boldsymbol{C} ; n=9\right.$ experiments). ${ }^{* *} p=0.002,{ }^{*} p<0.05$, and N.S., $p>0.05$ by Ztest againstzero.

syn-GCaMP6s in V1. To provide the excitation necessary to see the effects of disinhibition, we drove the network with a visual stimulus (a drifting grating presented for $600 \mathrm{~ms}$ ) while activating a single VIP (Fig. 6A). This protocol produced a disinhibitory effect both during awake and isoflurane anesthetized states (Fig. $6 B-D)$ ). Across 27 experiments (pooled awake and anesthetized data), we classified cells as disinhibited (33/638 cells) if their visual responses increased $>2 \times \mathrm{SD}$ during the VIP activation, as inhibited (6/638 cells) if they decreased $>2 \times \mathrm{SD}$, and as unchanged otherwise (599 cells). Because the inhibited cells formed $<1 \%$ of all cells, we did not analyze them further, though we note they may be SOMs based on their occurrence and inhibition by VIPs. The disinhibited cells were located significantly closer to the activated VIP than all imaged cells (Fig. 6E; disinhibited cells $66 \pm 9 \mu \mathrm{m}$ and all cells $101 \pm 2 \mu \mathrm{m}, p=0.002$ by rank sum test) indicating that VIPs have a local effect on neural activity in vivo. Plotting the change in visual responses upon VIP activation in all cells as a function of distance (Fig. $6 F$ ) suggests that VIPs have an effective disinhibitory radius of $\sim 120 \mu \mathrm{m}(120-180$ $\mu \mathrm{m}$ being the first bin not significantly above zero, $p=0.06$ by $Z$ test against zero).

Because VIPs tend to be activated during locomotion (Fu et al., 2014), we divided the data into anesthetized, awake stationary and awake locomotion epochs and repeated the analysis in Figure 6F. Data were similar in anesthetized (Fig. 7A) and awake stationary states (Fig. $7 B$ ), showing a distance-dependent decrease in disinhibition with significant disinhibition within $60 \mu \mathrm{m}$ from the stimulated VIP. However, during locomotion epochs the distance dependence was scrambled (Fig. 7C). This is likely because of the increased neuronal activity and recruitment of many more VIPs than the stimulated one during locomotion. Together, our data suggest that the effective lateral reach of a single VIP cell is $\sim 60-120 \mu \mathrm{m}$ and they can form holes in the blanket of inhibition of this size.

\section{Discussion}

Here we show with loss-of-function experiments that cortical lateral inhibition is mediated by SOMs (Fig. 1), that VIPs can block this lateral inhibition, and that single VIPs can have a highly localized disinhibitory effect on the surrounding network. Our results are consistent with previous indirect evidence that SOMs mediate FDDI (Kapfer et al., 2007; Silberberg and Markram, 2007; Murayama et al., 2009) and our data on localized output of VIPs is consistent with previous knowledge of their morphology (Kawaguchi and Kubota, 1996; Bayraktar et al., 2000; Tahvildari et al., 2012; Lee et al., 2013). Our results suggest that VIPs make $\sim 240 \mu \mathrm{m}$ diameter disinhibitory holes in the blanket of inhibition mediated by SOMs (Fig. 6). These results are consistent with the naturally occurring distance dependence of VIP-PC activity correlations (Figs. 3, 4). A recent report also concluded that VIPs, in contrast to SOMs and PVs, have a uniquely localized disinhibitory effect with a radius of $<200 \mu \mathrm{m}$ (Zhang et al., 2014). Our results indicate that morphologically VIP axons extend $\sim 233$ $\mu \mathrm{m} / 2=116 \mu \mathrm{m}$ laterally, whereas functionally inhibiting SOMs within a reach of $\sim 112 \mu \mathrm{m}$ (Fig. 2; see Results); VIPs have increased correlation with cells $\sim 75-150 \mu \mathrm{m}$ away laterally depending on the behavioral state of the animal (Figs. 3, 4); and when activated optogenetically, single VIPs can disinhibit cells within $\sim 60-120 \mu \mathrm{m}$ depending on behavioral state (Figs. 6,7 ). Our results further suggest that the localized spatial effect of single VIP activity is not seen during locomotion, potentially due to increased neuronal, and specifically VIP (Fu et al., 2014), activity (Figs. $3 \mathrm{H}, I, 7 \mathrm{C}$ ). Although our in vitro results may be underestimates due to the inevitability of cut processes in brain slices, the similarity of the in vivo results increases their credibility, and together the data suggest a $\sim 120 \mu \mathrm{m}$ lateral radius of effect for single VIPs. We note that as all our recordings were from layer $2 / 3$, they only apply there, and it is possible that VIPs mediate qualitatively different effects in the deeper layers where some of them project axons (Fig. $2 A$ ).

VIPs may be active individually, e.g., during low-activity states or a specific input from prefrontal cortex (Harris and Thiele, 2011; Zhang et al., 2014). This mode of activity may thus form highly localized disinhibited patches of cortex. Alternatively, a few closely spaced VIPs may be preferentially activated together, thus forming larger patches of disinhibited cortex. As the presence of sensory stimulation (Fig. 6) was required for seeing the disinhibitory effect of single VIP activation (data not shown) the spatiotemporal coincidence of excitation and a disinhibitory hole may be necessary to use the hole in blanket inhibition.

In any case, our results thus demonstrate a circuit mechanism that could be used to open up preferential channels of transmission in an otherwise widely inhibited cortical tissue (Karnani et al., 2014). This type of local control could be use to dynamically sculpt selective cortical circuits out of a neural network type of connectivity matrix, and use them to implement specific perceptions, behaviors, memory states or, more generally, dynamical attractors. In addition, the opening of hole in this inhibitory blanket, could be also potentially useful as a mechanism to generate a "spotlight of attention" (Harris and Thiele, 2011; Zhang et al., 2014). In vivo two-photon optogenetic experiments, such as the ones described here, in principle, could be combined with behavioral training to explore the effects of 
the selective activation of VIP interneurons on the emergent functions of the neocortex.

\section{References}

Adesnik H, Bruns W, Taniguchi H, Huang ZJ, Scanziani M (2012) A neural circuit for spatial summation in visual cortex. Nature 490:226-231. CrossRef Medline

Bayraktar T, Welker E, Freund TF, Zilles K, Staiger JF (2000) Neurons immunoreactive for vasoactive intestinal polypeptide in the rat primary somatosensory cortex: morphology and spatial relationship to barrelrelated columns. J Comp Neurol 420:291-304. CrossRef Medline

Fino E, Yuste R (2011) Dense inhibitory connectivity in neocortex. Neuron 69:1188-1203. CrossRef Medline

Fu Y, Tucciarone JM, Espinosa JS, Sheng N, Darcy DP, Nicoll RA, Huang ZJ, Stryker MP (2014) A cortical circuit for gain control by behavioral state. Cell 156:1139-1152. CrossRef Medline

Harris KD, Mrsic-Flogel TD (2013) Cortical connectivity and sensory coding. Nature 503:51-58. CrossRef Medline

Harris KD, Thiele A (2011) Cortical state and attention. Nat Rev Neurosci 12:509-523. CrossRef Medline

Hartline HK, Wagner HG, Ratliff F (1956) Inhibition in the eye of Limulus. J Gen Physiol 39:651-673. CrossRef Medline

Inan M, Blázquez-Llorca L, Merchán-Pérez A, Anderson SA, DeFelipe J, Yuste R (2013) Dense and overlapping innervation of pyramidal neurons by chandelier cells. J Neurosci 33:1907-1914. CrossRef Medline

Kapfer C, Glickfeld LL, Atallah BV, Scanziani M (2007) Supralinear increase of recurrent inhibition during sparse activity in the somatosensory cortex. Nat Neurosci 10:743-753. CrossRef Medline

Karnani MM, Agetsuma M, Yuste R (2014) A blanket of inhibition: functional inferences from dense inhibitory connectivity. Curr Opin Neurobiol 26:96-102. CrossRef Medline

Kawaguchi Y, Kubota Y (1996) Physiological and morphological identification of somatostatin- or vasoactive intestinal polypeptide-con- taining cells among GABAergic cell subtypes in rat frontal cortex. J Neurosci 16:2701-2715. Medline

Lee S, Kruglikov I, Huang ZJ, Fishell G, Rudy B (2013) A disinhibitory circuit mediates motor integration in the somatosensory cortex. Nat Neurosci 16:1662-1670. CrossRef Medline

Murayama M, Pérez-Garci E, Nevian T, Bock T, Senn W, Larkum ME (2009) Dendritic encoding of sensory stimuli controlled by deep cortical interneurons. Nature 457:1137-1141. CrossRef Medline

Packer AM, Yuste R (2011) Dense, unspecific connectivity of neocortical parvalbumin-positive interneurons: a canonical microcircuit for inhibition? J Neurosci 31:13260-13271. CrossRef Medline

Packer AM, Peterka DS, Hirtz JJ, Prakash R, Deisseroth K, Yuste R (2012) Two-photon optogenetics of dendritic spines and neural circuits. Nat Methods 9:1202-1205. CrossRef Medline

Packer AM, Russell LE, Dalgleish HW, Häusser M (2015) Simultaneous alloptical manipulation and recording of neural circuit activity with cellular resolution in vivo. Nat Methods 12:140-146. CrossRef Medline

Pfeffer CK, Xue M, He M, Huang ZJ, Scanziani M (2013) Inhibition of inhibition in visual cortex: the logic of connections between molecularly distinct interneurons. Nat Neurosci 16:1068-1076. CrossRef Medline

Pi HJ, Hangya B, Kvitsiani D, Sanders JI, Huang ZJ, Kepecs A (2013) Cortical interneurons that specialize in disinhibitory control. Nature 503: 521-524. CrossRef Medline

Silberberg G, Markram H (2007) Disynaptic inhibition between neocortical pyramidal cells mediated by Martinotti cells. Neuron 53:735-746. CrossRef Medline

Tahvildari B, Wölfel M, Duque A, McCormick DA (2012) Selective functional interactions between excitatory and inhibitory cortical neurons and differential contribution to persistent activity of the slow oscillation. J Neurosci 32:12165-12179. CrossRef Medline

Zhang S, Xu M, Kamigaki T, Hoang Do JP, Chang WC, Jenvay S, Miyamichi K, Luo L, Dan Y (2014) Selective attention: long-range and local circuits for top-down modulation of visual cortex processing. Science 345:660-665. CrossRef Medline 